\title{
A Qualitative Study into Dependent Relationships and Voluntary Informed Consent for Research in Pediatric Oncology
}

\author{
Sara A. S. Dekking ${ }^{1} \cdot$ Rieke van der Graaf $^{1} \cdot$ Antoinette Y. N. Schouten-van Meeteren $^{2} \cdot$ \\ Marijke C. $\operatorname{Kars}^{1} \cdot$ Johannes J. M. van Delden ${ }^{1}$
}

Published online: 11 January 2016

(C) The Author(s) 2016. This article is published with open access at Springerlink.com

\begin{abstract}
Background In pediatric oncology, many oncologists invite their own patients to participate in research. Inclusion within a dependent relationship is considered to potentially compromise voluntariness of consent. Currently, it is unknown to what extent those involved in pediatric oncology experience the dependent relationship as a threat to voluntary informed consent, and what they see as safeguards to protect voluntary informed consent within a dependent relationship.
\end{abstract}

Electronic supplementary material The online version of this article (doi:10.1007/s40272-015-0158-9) contains supplementary material, which is available to authorized users.

Sara A. S. Dekking

S.A.S.Dekking@umcutrecht.nl

Rieke van der Graaf

R.vanderGraaf@umcutrecht.nl

Antoinette Y. N. Schouten-van Meeteren

A.Y.N.Schouten@amc.uva.nl

Marijke C. Kars

M.C.Kars@umcutrecht.nl

Johannes J. M. van Delden

J.J.M.vanDelden@umcutrecht.nl

1 Department of Medical Humanities, Julius Center for Health Sciences and Primary Care, University Medical Center Utrecht, P.O. Box 85500, 3508 GA Utrecht, The Netherlands

2 Department of Pediatric Oncology, Emma Children's Hospital, Amsterdam Medical Center, P.O. Box 22660, 1100 DD Amsterdam, The Netherlands
Aim We performed a qualitative study among key actors in pediatric oncology to explore their experiences with the dependent relationship and voluntary informed consent.

Methods We conducted three focus groups and 25 semistructured, in-depth interviews with pediatric oncologists, research coordinators, Research Ethics Committee members, parents of children with cancer, and adolescents with cancer.

Results Professionals regarded the dependent relationship both as a potential threat to and as a positive influence on voluntary decision making. Parents and adolescents did not feel as though dependency upon the oncologist influenced their decisions. They valued the involvement of their own physician in the informed consent process. The professionals suggested three strategies to protect voluntariness: emphasizing voluntariness; empowering families; involvement of an independent person.

Conclusions Although the dependent relationship between pediatric oncologists, patients and parents may be problematic for voluntary informed consent, this is not necessarily the case. Moreover, the involvement of treating physicians may even have a positive impact on the informed consent process. Although we studied pediatric oncology, our results may also apply to many other fields of pediatric medicine where research and care are combined, for example, pediatric rheumatology, neurology and nephrology. Clinical trials in these fields are inevitably often designed, initiated and conducted by medical specialists closely involved in patient care. 


\section{Key Points}

The assumption that dependent relationships have a potentially problematic influence on voluntary informed consent for pediatric oncology research was supported by some of our respondents.

At the same time, the dependent relationship was not always experienced as a threat to voluntary informed consent for research.

Some pediatric oncology actors even regarded the treating relationship between pediatric oncologists, parents and patients as potentially valuable to voluntary decision making.

\section{Introduction}

Since in pediatric oncology the provision of treatment is closely combined with research, many oncologists are both clinicians and researchers and include their own patients in studies [1]. Guidelines for human subject research demand that physicians do not enroll their own patients in research $[2,3]$. The dependent relationship between them and their patients may compromise the voluntariness of the patient's consent, since this relationship may constitute an undue influence [2-4]. In ethical guidelines and literature, the presence of undue influence on patient decision making is considered to compromise voluntary informed consent for research $[2,5]$.

Currently, it is unknown to what extent actors in pediatric oncology experience the dependent relationship as a threat to voluntary informed consent, and what they see as safeguards to protect voluntary informed consent within a dependent relationship. In order to explore these two questions, we conducted a qualitative study into the experiences of pediatric oncology actors with voluntary informed consent when the treating oncologist is involved in the informed consent process. Insight into these experiences is an important factor for the ethical evaluation of voluntary informed consent in pediatric oncology [6].

Previous qualitative studies have not specifically investigated the experiences of those involved in pediatric oncology with voluntary informed consent within a dependent relationship, but have mainly described experiences of parents and physicians with the informed consent process for pediatric oncology trials in general [7-17]. Moreover, most studies focus on the disclosure and comprehension aspect of informed consent rather than on voluntariness, or they explore the satisfaction of families with the informed consent process and their suggestions for improvement [7-10, 12-17]. A study by Miller and Nelson [11] addressed voluntary parental decision making, but discussed demographic and contextual factors that could affect parental perceptions of voluntariness rather than the influence of inclusion within the patient-physician relationship.

Therefore, in this paper we studied the dependent relationship in pediatric oncology and its potential influence on voluntary informed consent for research. We performed a qualitative study among key actors in pediatric oncology in which we explored their experiences with this relationship.

\section{Materials and Methods}

A qualitative study design allows for in-depth exploration of a topic and is therefore most suited to capture the experiences of those involved in pediatric oncology. As a first exploration of the topic, we conducted three homogenous focus groups: one with Dutch pediatric oncologists, one with Research Ethics Committee (REC) members, and one with parents of children with cancer. To validate and deepen our insights, a second stage of in-depth interviews was performed. We conducted 25 individual interviews with pediatric oncologists, research coordinators, parents of children with cancer, and adolescents with cancer. The checklist with consolidated criteria for reporting qualitative studies (COREQ) is available as electronic supplementary material (Online Resource 1).

\subsection{Sample}

The inclusion criterion for the pediatric oncologists, research coordinators, parents and adolescents was to have been actively involved in inclusion for pediatric oncology trials. For the pediatric oncologists and research coordinators, this means that they should regularly inform families about available studies and perform informed consent procedures. For parents and adolescents active involvement means they have been approached for a pediatric oncology study and have had informed consent conversations, regardless of the final decision; parents and adolescents who refused one or more studies were eligible for the focus group or interviews. Also, for the parents and adolescents, the moment of being approached about participation in an oncology study, for their child or for themselves, should have been less than 2 years ago. The inclusion criterion for REC members was to be or have been a member of an REC at a pediatric oncology center. All respondents had to be able to speak the Dutch language. In addition, for all respondents, we aimed for a large variety in age, gender, 
Table 1 Characteristics of professionals

\begin{tabular}{|c|c|c|c|}
\hline & Focus group (no. of participants) & Interviews (no. of participants) & Total \\
\hline Pediatric oncologists & 7 (focus group and expert meeting) & 9 & 16 \\
\hline \multicolumn{4}{|l|}{ Gender } \\
\hline Male & 5 & 3 & 8 \\
\hline Female & 2 & 6 & 8 \\
\hline \multicolumn{4}{|l|}{ Experience (years) } \\
\hline $5-10$ & 2 & 3 & 5 \\
\hline $11-15$ & 1 & 4 & 5 \\
\hline $16-20$ & 1 & 1 & 2 \\
\hline$>20$ & 3 & 1 & 4 \\
\hline \multicolumn{4}{|c|}{ Areas of interest: clinical oncology $\mathrm{y}^{\mathrm{a}}$} \\
\hline No specific & 0 & 2 & 2 \\
\hline Solid tumors & 5 & 4 & 9 \\
\hline Lymphomas & 2 & 2 & 4 \\
\hline Leukemia & 3 & 5 & 8 \\
\hline Stem cell transplantation & 3 & 1 & 4 \\
\hline Histiocytosis & 0 & 2 & 2 \\
\hline Myelodysplastic syndrome & 1 & 0 & 1 \\
\hline \multicolumn{4}{|l|}{ Areas of interest: research ${ }^{\mathrm{b}}$} \\
\hline Clinical drug trials & 6 & 6 & 12 \\
\hline Laboratory research & 1 & 5 & 6 \\
\hline Supportive care & 2 & 4 & 6 \\
\hline Palliative care & 2 & 1 & 3 \\
\hline Stem cell transplantation & 2 & 2 & 4 \\
\hline Research coordinators & & 3 & 3 \\
\hline \multicolumn{4}{|l|}{ Gender } \\
\hline Male & & 1 & 1 \\
\hline Female & & 2 & 2 \\
\hline \multicolumn{4}{|l|}{ Experience (years) } \\
\hline $0-5$ & & 2 & 2 \\
\hline $5-10$ & & 1 & 1 \\
\hline REC members & 4 & & 4 \\
\hline \multicolumn{4}{|l|}{ Gender } \\
\hline Male & 1 & & 1 \\
\hline Female & 3 & & 3 \\
\hline \multicolumn{4}{|l|}{ Experience in REC (years) } \\
\hline $5-10$ & 1 & & 1 \\
\hline $10-15$ & 3 & & 3 \\
\hline \multicolumn{4}{|l|}{ Background } \\
\hline Medical ethics & 1 & & 1 \\
\hline Oncology & 1 & & 1 \\
\hline Pediatric rheumatology & 1 & & 1 \\
\hline Clinical pharmacology & 1 & & 1 \\
\hline
\end{tabular}

Adapted with permission from: Dekking et al. [26]

REC Research Ethics Committee

${ }^{a}$ Pediatric oncologists could have various areas of interest in clinical oncology. Therefore, these numbers do not add up to 16

b Pediatric oncologists could have various areas of interest in research. Therefore, these numbers do not add up to 16 
Table 2 Characteristics of parents and their children

\begin{tabular}{|c|c|c|c|}
\hline & Focus group (no. of participant) & Interviews (no. of participants) & Total \\
\hline Parents & 9 & 8 & 17 \\
\hline \multicolumn{4}{|l|}{ Gender } \\
\hline Male & 5 & 2 & 7 \\
\hline Female & 4 & 6 & 10 \\
\hline \multicolumn{4}{|l|}{ Age (years) } \\
\hline 34-39 & 2 & 3 & 5 \\
\hline $40-44$ & 1 & 3 & 4 \\
\hline $45-50$ & 5 & 3 & 8 \\
\hline \multicolumn{4}{|l|}{ Education } \\
\hline Primary, lower secondary general, or lower vocational & 2 & 0 & 2 \\
\hline Higher secondary general or intermediate vocational & 3 & 4 & 7 \\
\hline Higher vocational or university & 4 & 4 & 8 \\
\hline Children of these parents & $6^{\mathrm{a}}$ & $8^{\mathrm{b}}$ & 14 \\
\hline \multicolumn{4}{|l|}{ Gender } \\
\hline Male & 6 & 4 & 10 \\
\hline Female & 0 & 4 & 4 \\
\hline \multicolumn{4}{|l|}{ Age (years) } \\
\hline $0-4$ & 0 & 2 & 2 \\
\hline $5-9$ & 2 & 0 & 2 \\
\hline $10-14$ & 2 & 4 & 6 \\
\hline $15-19$ & 2 & 2 & 4 \\
\hline \multicolumn{4}{|l|}{ Diagnosis } \\
\hline Acute lymphoblastic leukemia & 2 & 2 & 4 \\
\hline Acute myeloid leukemia & 0 & 1 & 1 \\
\hline Leukemia (undefined) & 0 & 1 & 1 \\
\hline Chronic myeloid leukemia & 2 & 0 & 2 \\
\hline Rhabdomyosarcoma & 1 & 0 & 1 \\
\hline Burkitt lymphoma & 1 & 0 & 1 \\
\hline Hepatoblastoma & 0 & 1 & 1 \\
\hline Osteosarcoma & 0 & 1 & 1 \\
\hline Ewing sarcoma & 0 & 1 & 1 \\
\hline Brain tumor (high grade glioma) & 0 & 1 & 1 \\
\hline \multicolumn{4}{|l|}{ Medical situation } \\
\hline Finished standard treatment, under control of the hospital & 3 & 4 & 7 \\
\hline Under treatment within study protocol & 3 & 3 & 6 \\
\hline Palliative care; only pain medication & 0 & 1 & 1 \\
\hline
\end{tabular}

Adapted with permission from: Dekking et al. [26]

a The nine parents of the focus group together had six children, since there were three parent couples

b The interviewed parents were different parents than those from the focus group. There were no couples among the eight parents we interviewed, so these parents represent eight children. Four of these children were not interviewed themselves, and four of them (adolescents) were. The characteristics of these eight children are presented here. The characteristics of the four adolescents who were interviewed themselves are also separately presented in Table 3

types of cancer, and experience with research participation. See Table 1 for the characteristics of the professionals (pediatric oncologists, research coordinators and REC members), Table 2 for the parents and their children, and Table 3 for the adolescents. See Fig. 1 for a flow chart of the different respondents.

\subsubsection{Focus Groups}

Pediatric oncologists were recruited from the seven pediatric oncology centers in the Netherlands, one from each center. Our two pediatric oncology project advisors contacted the heads of the pediatric oncology centers, asking 
Table 3 Characteristics of adolescents

\begin{tabular}{ll}
\hline & Interviews (no. of participants) \\
\hline Adolescents & 5 \\
Gender & 3 \\
Male & 2 \\
Female & \\
Age (years) & 2 \\
13 & 1 \\
14 & 2 \\
15 & \\
Diagnosis & 1 \\
Acute lymphoblastic leukemia & 1 \\
Acute myeloid leukemia & 1 \\
Undefined leukemia & 1 \\
Brain tumor (high grade glioma) & 1 \\
Hodgkin lymphoma & \\
Medical situation & 3 \\
Finished treatment, under control of the hospital & 2 \\
Under treatment within study protocol & \\
\hline
\end{tabular}

them to invite one of their physicians who were regularly involved in informed consent discussions to take part in our focus group. Six pediatric oncologists took part, one could not attend.

Also, for the focus group with REC members, our goal was to include members from all seven Dutch pediatric oncology centers, but due to practical reasons, five of them could not send a member to represent their center in the focus group. From one center, one REC member attended; from another center, two members were present. In order to increase the number of participants, we approached the central review committee of the Netherlands (CCMO), from which one person could participate. Thus, the focus group involved four participants from three different ethical committees.

Parents of children with cancer for the focus group were all recruited through one center for pragmatic reasons. We considered that organizing a meeting for parents situated at different centers would entail too much burden (in terms of travel time) and was therefore unfeasible. In principle, all parents were eligible whose child was participating in or had participated in a pediatric oncology study. We aimed at maximal variation in the types of studies children (had) participated in for different kinds of malignancies. More specifically, we aimed for two to three patients taking part in a phase I-II study, two to three in a phase III study and two to three in a supportive care study, as the main study the child (had) participated in. In addition, children could have been invited for and involved in other studies. A research nurse contacted 12 parents of eight children by telephone, on the basis of the child's study participation.
These parents all accepted the invitation to participate in the focus group. In total nine parents of six children attended; four mothers and five fathers. Three parents could not attend, because of practical reasons.

\subsubsection{Interviews}

Pediatric oncologists from the seven Dutch pediatric oncology centers were contacted via the heads of these centers and via two of our project advisors, who contacted their colleagues and provided them with a description of our study and its aims. Also, they indicated that the pediatric oncologists should contact SD (first author) if they were interested in taking part in an interview. Inclusion in the study was continuous via convenience sampling; all interested pediatric oncologists were considered eligible to take part as long as they had experience with including their patients in oncology studies and performing informed consent conversations. In addition, we asked participating pediatric oncologists whether they knew colleagues whom we could approach to take part in an interview. Research coordinators were recruited from two centers, since not all Dutch pediatric oncology centers employ research coordinators.

Parents and adolescents were approached through a call on the website of the Dutch Association for Parents, Children and Cancer (VOKK) and via physicians and research nurses of three pediatric oncology centers. Here also, inclusion in the study was continuous via convenience sampling, as all parents and adolescents with cancer were eligible who had been invited for research, 
Fig. 1 Flow chart of respondents. Numbers in bold added up $=$ the total number of respondents $=45$. Adapted with permission from: Dekking et al. [26]

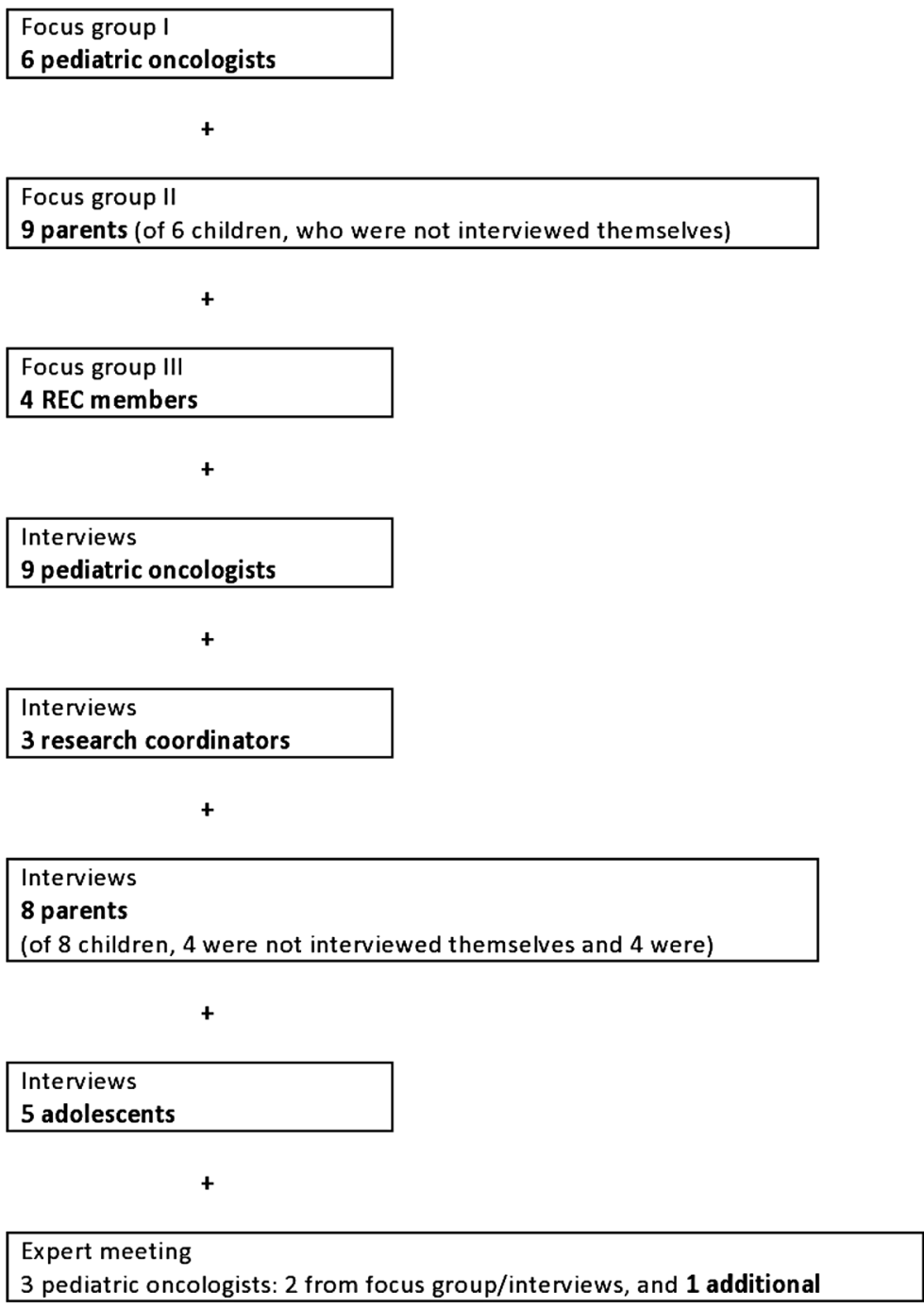

regardless of type of study. In some cases, physicians recruited their own patients and parents of these patients for our study. In one case, the recruiting physician was also the investigator of a study the child was participating in. The physician approached a family about our study, gave them the information form and asked whether they were interested in participating. If so, the parent could contact the investigator of this study (first author SD) to make an appointment for the interview(s). Before each interview, informed consent was obtained by SD.

We interviewed nine pediatric oncologists from five different centers (three interested pediatric oncologists, from two different centers, were not interviewed in the end, because of logistic reasons), three research coordinators, eight parents of eight different children, and five adolescents. Four of these adolescents were the children of parents we interviewed. For one adolescent, the parents were not interviewed.

\subsection{Data Collection}

Focus groups lasted 2 hours each. Topics were formulated after examination of the relevant literature and two 1-week internships of SD at two Dutch pediatric oncology centers, where she attended consultations between physicians, parents and patients, and gathered expert knowledge from pediatric oncologists and research nurses.

Semi-structured, in-depth interviews were conducted according to a predefined topic list (Online Resource 2).

All but one interview took place at a pediatric oncology center. One interview, with an adolescent boy, took place at home. Data collection took place from March 2013 to January 2015.

The study was approved by the REC of the University Medical Center Utrecht. Parents and adolescents provided written informed consent for their participation and, if applicable, parents also provided written consent for their child's participation. 


\subsection{Analysis}

The analysis was carried out according to thematic analysis, a method for identifying, analyzing, and reporting themes within data [18]. Our themes were identified at the semantic level, meaning that we started with describing the experiences of the respondents followed by an interpretation in the light of the existing literature [18]. The focus groups and interviews were transcribed verbatim and the data were imported into the software program NVivo 10, in order to facilitate the process of analysis.

SD was the main analyst. SD, MK and RG independently read two interviews, selected fragments of the data that were relevant in relation to the study purpose, and coded these fragments with appropriate labels. During a first meeting, all findings were compared and contrasted, which resulted in the initial code tree. During two more team meetings, we compared our interpretations of fragments of two new interviews and identified the appropriate labels for these fragments. We worked towards reaching consensus between the different team members, and aimed to align our interpretations of the data. During this phase, we developed the code tree into a more conceptual code structure. Then SD coded the focus groups and interviews in line with this shared interpretation of the first four interviews (that is, based on the conceptual code structure). The appropriate codes were grouped into conceptual categories or themes on the basis of their content, meaning and interrelationships. SD described these themes, their characteristics and the associations between them. To ensure reliability, these themes and accompanying descriptions were continuously discussed during team meetings, providing SD with a shared conceptual basis for the remainder of the coding process.

To enhance the validity of our findings, we held an expert meeting with pediatric oncologists in the last phase of data collection. We discussed our preliminary results to assess whether these were an accurate representation of pediatric oncology practice and to obtain additional data. In general, the oncologists recognized our presentation of the informed consent process and of their experiences with including their own patients.

\section{Results}

\subsection{The Role of the Dependent Relationship}

We identified three ways in which our respondents experienced the influence of the dependent relationship on voluntary informed consent, i.e., potentially problematic influence, minimal or no influence and positive influence.
Representative quotations were chosen to illustrate the themes identified (Table 4).

\subsubsection{Potentially Problematic Influence}

The pediatric oncologists felt that patients and their parents are extremely dependent upon them for treatment and to safeguard the possibility of a cure. They thought that this dependency could compromise voluntary informed consent because parents have an interest in maintaining a good relationship with their physician (quote 1 in Table 4).

Also, research coordinators thought that sometimes parents were reluctant to say 'no' to one of the oncologists. In addition, a research coordinator who also had extensive caring tasks described situations in which she thought that parents felt guilty when their child decided not to participate (quote 2 in Table 4).

Only one father thought that the dependent relationship with the treating physician of his son may have been a factor in his deliberations about whether to consent to studies that were offered shortly after hearing his son's cancer diagnosis (quote 3 in Table 4).

One adolescent boy indicated that he had wondered what would happen if he refused to take part in the studies that were offered to him, and if it would affect his future care or the way his oncologist perceived him. When he asked the oncologists about this, they told him that nothing would happen if he refused, and this sufficiently reassured him.

\subsubsection{Minimal or No Influence}

Oncologists believed that they generally have no influence on decisions of parents about research. They thought that the majority of parents make these decisions completely or mainly independently, as a family, without feeling pressure from the oncologists or others.

Although parents recognized being and feeling strongly dependent on their oncologist, they said that this had no influence on their decisions about their child's research participation. They made their own decisions, on the basis of criteria they considered important. They either hoped that a study could benefit their child or expected it would at least not have a negative influence on their child's general treatment. In addition, they considered studies with very low risk and burden, such as having some extra blood taken at regular blood drawing moments, as a simple way to contribute to improvement of therapy for children with cancer (quote 4 in Table 4).

Also, because of their experiences with their sick child, parents were even more motivated to contribute to the 
Table 4 Quotes from focus groups and interviews

\begin{tabular}{|c|c|c|}
\hline Theme & Quote & Respondent \\
\hline \multirow[t]{3}{*}{$\begin{array}{l}\text { Potentially problematic } \\
\text { influence }\end{array}$} & 1 & $\begin{array}{l}\text { Pediatric oncologist: 'These people have a general interest in you as their physician; you have to make } \\
\text { sure that their child survives. In oncology this is of course even stronger, since it is about life and death. } \\
\text { So they have a certain interest in staying friends with the physician. Not everyone understands that, but } \\
\text { most do. So there arises some sort of problem that people might think they have to say yes' }\end{array}$ \\
\hline & 2 & $\begin{array}{l}\text { Research coordinator: 'One girl said that she did not want to take part because she did not want to come } \\
\text { [to the hospital] an extra time. And then the mother said: "Sorry Jane, we really tried to talk her into it, } \\
\text { but it didn't work out". And then I noticed that something went wrong, because they apologized to me, } \\
\text { while I am supposed to be independent' }\end{array}$ \\
\hline & 3 & $\begin{array}{l}\text { Parent: 'When you get a request in the first six weeks after diagnosis, you think like: "what if I say no } \\
\text { now, will that have an influence on the chance that my child will get better?" In whatever way possible. } \\
\text { Because then I would oppose the oncologist, while he wants to do a certain study and then he will } \\
\text { regard you differently and will have less attention for you, because you do not take part in the study' }\end{array}$ \\
\hline \multirow[t]{2}{*}{ Minimal or no influence } & 4 & $\begin{array}{l}\text { Parent: 'Your question seems to imply that as a parent you have more confidence in your treating } \\
\text { oncologist than in another doctor or a research nurse. And that you feel some sort of social pressure to } \\
\text { take part in the research. No ... you just consider what kind of research it is. What will it do to my } \\
\text { child? Does the moment suit me etc.? You act very rationally, at least I do. Just considering whether the } \\
\text { study is in line with what your child can handle. And not really with the person who introduces it' }\end{array}$ \\
\hline & 5 & $\begin{array}{l}\text { Parent: 'For Jesse it had a large impact that a boy he became friends with passed away, which really } \\
\text { depressed him and us of course. And then we thought, there is nothing we can do for this boy, he's not } \\
\text { here anymore. So we said we will participate in all studies they ask us for, and he also wanted to take } \\
\text { part in everything, just to be able to do something back' }\end{array}$ \\
\hline Positive influence & 6 & $\begin{array}{l}\text { Parent: 'If it becomes life threatening, you just completely rely on your treating physician, your treating } \\
\text { oncologist, because he shares your experiences from the beginning. And if some external person comes } \\
\text { in who is also wearing a white coat, who might know even more, but I do not know this person, then I } \\
\text { check the eyes of my treating oncologist, what they look like' }\end{array}$ \\
\hline Empowering families & 7 & $\begin{array}{l}\text { REC member: 'It is also about the terminology you use. If you just say to parents that they are the ones } \\
\text { who decide what happens to their child, not me. If you start with giving them the responsibility. They } \\
\text { have to make the decisions' }\end{array}$ \\
\hline $\begin{array}{l}\text { Involvement of an } \\
\text { independent person }\end{array}$ & 8 & $\begin{array}{l}\text { REC member: 'One of the really difficult aspects is that it is such a severe disease and that people are } \\
\text { already extremely dependent upon the treating physician. And if you say: well then just say no to } \\
\text { someone else, because that is what it comes down to, since the physician himself is often still the one to } \\
\text { ask ... That you do not have the feeling that their situation is improved or that the child or the parents } \\
\text { are better protected if you try to resolve it like that' }\end{array}$ \\
\hline
\end{tabular}

REC Research Ethics Committee

improvement of therapy for other patients. A father explained why he and his son wanted to take part in research (quote 5 in Table 4).

The adolescents reported feeling no pressure from their oncologist or others and felt free to refuse participation if they wanted to. They were motivated to participate in studies and contribute to improve treatment for future patients with their disease. If they had sensed that their oncologist would prefer for them to take part in a certain study, this generally had no influence on their decisions.

\subsubsection{Positive Influence}

Pediatric oncologists explained that since they are the treating physician of the child, they are in the perfect position to guide families in their decision-making process. Because they know patients and their parents, they are able to provide information in an appropriate manner and to introduce the large number of studies in a way that it becomes feasible. They mentioned that protecting patients is necessary in order to maintain a positive treatment relationship. A person who is only a researcher does not have this interest in protecting the relationship. In addition, it was stated that if parents are clearly unable to make a decision about the research request, then the treating oncologist would decide not to enroll the child.

Parents mentioned that they appreciated the way the treating oncologist explained the research, which enabled them to make their own decisions. One mother said that if an unknown researcher invited them to participate in a study, she may even ask her son's treating oncologist for advice. For studies with a potential profound impact on their child's wellbeing, parents said they preferred having the study explained by their own physician (quote 6 in Table 4). 


\subsection{Strategies to Protect Voluntariness of Informed Consent}

\subsubsection{Emphasizing the Voluntary Nature of Participation}

The health care professionals indicated trying to safeguard voluntary informed consent by stressing that research participation is a free choice and that patients always have the right to withdraw. In addition, they emphasize that for them it does not matter what parents decide and that refusal would not influence the treating relationship.

Parents and adolescents recalled being told that research participation was voluntary. Therefore, they felt that it really was their decision to make and that they need not consent to all the offered studies.

\subsubsection{Empowering Families}

Both the pediatric oncologists and the REC members stressed the importance of ensuring that parents and older patients gain a sense of responsibility by making it clear that they are the ones in charge (quote 7 in Table 4).

Diminishing the asymmetry in knowledge was also regarded as a way to empower families. Providing pediatric cancer patients and their parents with honest and objective information, both written and verbal, was often emphasized as a means to create optimal circumstances for making deliberate and well-balanced decisions. For the majority of parents, it was very important to receive adequate information on a study, making clear what the impact on their child would be and in what way it could help to improve treatment.

An REC member suggested assigning a sort of 'medical coach' to families as a way to accomplish empowerment. This coach could advise them on where to find certain information or whom to approach for specific questions. The pediatric oncologists worried that letting a medical coach attend the informed consent conversations would disturb the dynamic between them and families.

\subsubsection{Involvement of an Independent Person}

Several pediatric oncology centers employ a clinical research team, which is responsible for the research logistics. The treating oncologist usually introduces the research, followed by a research nurse who further explains study details. The pediatric oncologists and research coordinators said they appreciated the different roles being more clearly separated this way.

One oncologist was cautious with regard to research nurses obtaining informed consent, since these individuals can be as influential as physicians.

The REC members recognized inclusion for pediatric oncology studies by the treating oncologist as potentially problematic, but they were not convinced of the advantages of delegating this task to someone else. They regarded it as unnatural to try and separate the two roles in such a relatively small medical practice like pediatric oncology, where all health care professionals know all children and their families (quote 8 in Table 4).

Parents indicated that usually it did not matter for them which 'white coat' would provide information and obtain informed consent. One mother expressed that she was approached by an independent researcher a couple of days in a row to take part in a study. This made her feel a bit pressured and the researcher came across as too pushy.

For the adolescents, it would have made no difference if an independent person such as a research nurse had obtained the informed consent. Especially in the beginning, everyone is new to them and could be one of the doctors. Later on, they felt confident that their treating oncologist would accept their decision to refuse. They realized they were free to make their own choices about research, regardless of the person who asked them to participate.

\section{Discussion}

We explored the experiences of pediatric oncologists, research coordinators, REC members, parents of a child with cancer, and adolescents with cancer with voluntary informed consent for medical research within a dependent relationship. Our main finding is that although dependency is experienced as an aspect of the treating relationship, its influence on voluntary informed consent for research in pediatric oncology is not necessarily negative. In general, both the professionals and the patients and parents themselves did not regard inclusion by the treating physician as problematic for voluntary informed consent. Moreover, professionals, parents and adolescents considered involvement of the physician in the informed consent process as valuable. This finding is in contrast with ethical guidelines for medical research and bioethical literature, which mainly focus on potentially adverse effects of the dependent relationship on voluntariness of consent for research $[2,3]$.

An explanation for this difference between the experiences of our respondents and what is generally assumed in bioethical thinking may be as follows: children with cancer who participate in research and their parents perhaps feel less 'vulnerable' than is often thought with respect to decision making on study participation [10, 12-14, 19], even though their own physician is involved in the informed consent process. Patients are considered vulnerable when they are relatively or absolutely incapable of protecting their interests [2], when there is an identifiably increased likelihood of incurring additional or greater 
wrong [20], or when they are especially prone to harm or exploitation [21]. In research ethics guidelines, vulnerability is generally a label that is applied to groups of research participants, such as pregnant women or children [22]. Recently, Luna [23] has proposed to look more closely to the situational aspects of potential research participants to assess whether certain characteristics or 'layers' render them vulnerable. As Luna argues, layers can be multiple; some may be related to social circumstances, while other layers may be related to problems with voluntary informed consent [22].

On the one hand, children with cancer and their parents are subject to several layers of vulnerability, most notably a severe, potentially fatal disease and a strong dependence on their treating physician, who is often also involved in the informed consent process. Obviously, the layer of the disease cannot be removed. Previously, we have argued that also the layer of the dependent relationship is difficult to resolve [4]. In pediatric oncology this may even be more difficult, since most pediatric oncologists are both involved in the treatment of children with cancer and informed consent discussions [1]. As such, the layer of the dependent relationship may influence those patients or parents who are vulnerable to the influence of authoritative figures such as physicians.

However, other aspects of the situation of children with cancer and their parents might render families less vulnerable when providing informed consent for research, which could reduce the influence of the two layers of a severe disease and inclusion for research by the treating physician. In general, despite being faced with the potentially fatal disease of their child, parents felt that they were able to manage requests for study participation, protect their own and their child's interests and make decisions based on their own preferences. Furthermore, we noticed that the experiences of parents and adolescents with their disease and that of others strongly shaped the way they perceived research, which increased their willingness to participate in research. Having the ability to help other children through research participation helped them give meaning to their own illness or that of their child, since it enabled them to create something positive out of a primarily negative situation. Hence, our respondents' decisions regarding research participation appeared deliberate and voluntary, and not overly and directly influenced by the ideas and opinions of the pediatric oncology professionals.

Even though children with cancer who participate in research and their parents may be less vulnerable than expected, it remains necessary to critically reflect on ways to safeguard voluntary consent within a dependent relationship, since this relationship may still constitute an undue influence to some families [24]. Emphasizing the voluntary nature of participating appeared a good strategy to make children with cancer and their parents aware that they need not consent and can always withdraw their permission once enrolled in a study. However, on its own it may be insufficient to ensure voluntary participation. The availability of an independent medical counselor could be valuable for patients and their parents, as long as this person is specifically concerned with protecting their interests and available to provide advice and guidance [9, 19]. The regular Dutch research practice offers patients and parents the option to deliberate with an independent doctor, for whom the name and telephone number are regularly provided in the patient information form. This procedure could be improved by actively approaching parents to offer them a consultation. As such, this is a way of empowering families.

A strong feature of our study is that we invited different groups of respondents, to assemble a variety of perspectives. A second strength is the combination of two different qualitative methods: focus groups and individual interviews. This enabled us to receive answers to our questions both in a setting in which respondents could discuss different topics and in a more personal setting, allowing each respondent to elaborate on their experiences.

However, some limitations to our study also apply. First, although the total number of respondents is not particularly low for a qualitative study, the sample size does not permit drawing definite conclusions.

Second, since we could only study situations as experienced by the different respondents, we cannot rule out that despite the absence of direct, experienced influence or pressure, more implicit influences (such as trust and confidence in the treating physician) may have played a role in the research-related decisions of parents and adolescents without them being aware of this.

Third, there may be a risk of bias in the interviewed parents and adolescent patients, due to five aspects of our study and its design. (1) Only those patients and parents who were well enough to participate could be approached, rather than those who had difficulty with coping with the disease. (2) Two of the parents were recruited through the Dutch Association for Parents, Children and Cancer. This may have affected their views on pediatric oncology studies, since parents of this association are usually more actively engaged with research. However, one of these two parents had the most reservations with respect to the conduct of research. (3) The parents' educational level was above average, and therefore they may have been relatively articulate and well informed. These three aspects together may have increased the ability of our interviewed parents and adolescents to make decisions without feeling pressure from health care professionals. (4) Leukemia was the most common diagnosis in children in our study. In general, cure 
rates for leukemia are higher than for other types of cancer [25]. This relatively optimistic prognosis may have decreased feelings of dependence. Subsequently, this could have positively influenced the way the interviewed parents and adolescents regarded the informed consent procedure and their decision-making process. However, leukemia is also the most common form of cancer in children younger than 15 years old [25], so in that respect, our study provides an accurate reflection of the practice of pediatric oncology. (5) Some children were still under treatment, whereas others had already finished their treatment. The former group of children and their parents may not have a complete perspective on their experiences with the informed consent process and voluntariness. Consequently, their perspectives could have been different from those who have finished their treatment.

A fourth and final limitation is that we only reflect from within the Dutch pediatric oncology context. Therefore, ethical issues and their implications could vary, due to differences between the pediatric oncology contexts in different countries. Still, we believe that our study findings provide a valuable direction for future research on dependent relationships and voluntary informed consent.

\section{Conclusion}

The dependent relationship between pediatric oncologists, patients and parents need not be problematic for voluntary informed consent, since parents and adolescents did not experience pressure to participate and felt able to make well-considered decisions. Furthermore, involvement of the physician may even have a positive impact on voluntary informed consent. Yet, we should remain cautious, since in some cases, dependency on the pediatric oncologists may influence more vulnerable patients and parents. To prevent compromises to voluntariness, the strategy to increase availability of an independent counselor could be a valuable option.

Acknowledgments We would like to thank all our respondents for their contributions to our study. In particular, we are grateful for the parents and adolescents who were willing to share their experiences with us in what we realize to be a very intense and difficult period in their lives. We also wish to thank the pediatric oncologists and research nurses who helped us with the inclusion of adolescents and parents for our study.

\section{Compliance with Ethical Standards}

Funding Funding for this article was provided by The Netherlands Organization for Health Research and Development (Grant Number 113203201). This funding body had no role in the study's design, the collection, analysis and interpretation of data, the writing of the manuscript and the decision to submit the manuscript for publication.
Conflict of interest Authors SD, RvdG, ASvM, MK and JvD declare that they have no conflict of interest.

Ethical approval The study protocol was approved by the Research Ethics Committee of the University Medical Center Utrecht. All procedures performed in studies involving human participants were in accordance with the ethical standards of the institutional and/or national research committee and with the 1964 Helsinki declaration and its later amendments or comparable ethical standards.

Informed consent Informed consent was obtained from all individual participants included in the study.

Open Access This article is distributed under the terms of the Creative Commons Attribution-NonCommercial 4.0 International License (http://creativecommons.org/licenses/by-nc/4.0/), which permits any noncommercial use, distribution, and reproduction in any medium, provided you give appropriate credit to the original author(s) and the source, provide a link to the Creative Commons license, and indicate if changes were made.

\section{References}

1. de Vries MC, Houtlosser M, Wit JM, Engberts DP, Bresters D, Kaspers GJ, et al. Ethical issues at the interface of clinical care and research practice in pediatric oncology: a narrative review of parents' and physicians' experiences. BMC Med Ethics. 2011;12:18.

2. Council for International Organizations of Medical Sciences (CIOMS). International Ethical Guidelines for Biomedical Research involving Human Subjects. 2002 (Ref Type: Report).

3. World Medical Association Declaration of Helsinki. ethical principles for medical research involving human subjects. JAMA. 2013;310(20):2191-4.

4. Dekking SA, van der Graaf R, van Delden JJ. Strengths and weaknesses of guideline approaches to safeguard voluntary informed consent of patients within a dependent relationship. BMC Med. 2014; 12:52.

5. Hewlett S. Consent to clinical research-adequately voluntary or substantially influenced? J Med Ethics. 1996;22(4):232-7.

6. Van Thiel GJMW, Van Delden JJM. Reflective equilibrium as a normative empirical model. Ethical Perspect. 2010;17(2):183-202.

7. Chappuy H, Doz F, Blanche S, Gentet JC, Pons G, Treluyer JM. Parental consent in paediatric clinical research. Arch Dis Child. 2006;91(2):112-6.

8. Chappuy H, Bouazza N, Minard-Colin V, Patte C, Brugieres L, Landman-Parker J, et al. Parental comprehension of the benefits/ risks of first-line randomised clinical trials in children with solid tumours: a two-stage cross-sectional interview study. BMJ Open 2013;3(5):1-8.

9. Eiser C, Davies H, Jenney M, Glaser A. Mothers' attitudes to the randomized controlled trial (RCT): the case of acute lymphoblastic leukaemia (ALL) in children. Child Care Health Dev. 2005;31(5):517-23

10. Kupst MJ, Patenaude AF, Walco GA, Sterling C. Clinical trials in pediatric cancer: parental perspectives on informed consent. J Pediatr Hematol Oncol. 2003;25(10):787-90.

11. Miller VA, Nelson RM. Factors related to voluntary parental decision-making in pediatric oncology. Pediatrics. 2012;129(5):903-9.

12. Stevens PE, Pletsch PK. Ethical issues of informed consent: mothers' experiences enrolling their children in bone marrow transplantation research. Cancer Nurs. 2002;25(2):81-7. 
13. Levi RB, Marsick R, Drotar D, Kodish ED. Diagnosis, disclosure, and informed consent: learning from parents of children with cancer. J Pediatr Hematol Oncol. 2000;22(1):3-12.

14. Simon C, Eder M, Raiz P, Zyzanski S, Pentz R, Kodish ED. Informed consent for pediatric leukemia research: clinician perspectives. Cancer. 2001;92(3):691-700.

15. Woodgate RL, Yanofsky RA. Parents' experiences in decision making with childhood cancer clinical trials. Cancer Nurs. 2010;33(1):11-8.

16. Eder ML, Yamokoski AD, Wittmann PW, Kodish ED. Improving informed consent: suggestions from parents of children with leukemia. Pediatrics. 2007;119(4):e849-59.

17. Baker JN, Leek AC, Salas HS, Drotar D, Noll R, Rheingold SR, et al. Suggestions from adolescents, young adults, and parents for improving informed consent in phase 1 pediatric oncology trials. Cancer. 2013;119(23):4154-61.

18. Braun V, Clarke V. Using thematic analysis in psychology. Qual Res Psychol. 2006;3:77-101.
19. Berg SL. Ethical challenges in cancer research in children. Oncologist. 2007;12(11):1336-43.

20. Hurst SA. Vulnerability in research and health care; describing the elephant in the room? Bioethics. 2008;22(4):191-202.

21. Lange MM, Rogers W, Dodds S. Vulnerability in research ethics: a way forward. Bioethics. 2013;27(6):333-40.

22. Luna F, Vanderpoel S. Not the usual suspects: addressing layers of vulnerability. Bioethics. 2013;27(6):325-32.

23. Luna F. Elucidating the concept of vulnerability. Layers not labels. Int J Fem Approaches Bioethics. 2009;1:120-38.

24. Pinxten W, Nys H, Dierickx K. Regulating trust in pediatric clinical trials. Med Health Care Philos. 2008;11(4):439-44.

25. Siegel RL, Miller KD, Jemal A. Cancer statistics, 2015. CA Cancer J Clin. 2015;65(1):5-29.

26. Dekking SA, van der Graaf R, Kars MC, Beishuizen A, de Vries MC, van Delden JJ. Balancing research interests and patient interests: a qualitative study into the intertwinement of care and research in paediatric oncology. Pediatr Blood Cancer. 2015;62:816-22. 